\title{
Confiabilidad de la determinación del sexo fetal usando plasma materno (1)
}

\author{
Scheffer PG, van der Schoot CE, Page-Christiaens GC, Bossers B, van Erp F, de \\ Haas M. Obstet Gynecol 2010;115(1):117-26.
}

Análisis crítico: Jorge Carvajal C., $P h D^{1}$, Claudio Vera P-G., MSc ${ }^{1,2}$

1 Unidad de Medicina Materno-Fetal. Departamento de Obstetricia y Ginecología, ${ }^{2}$ Unidad de Medicina Basada en
Evidencia, Facultad de Medicina, Pontificia Universidad Católica de Chile.

\section{RESUMEN}

Objetivo: Determinar la acuciosidad diagnóstica de la determinación no invasiva del sexo fetal en plasma materno. Métodos: Todas las pacientes consecutivas, a quienes se realizó determinación del sexo fetal desde 2003 hasta el 2009, fueron incluidas en el estudio. Se realizó reacción de polimerasa en cadena, en tiempo real, para el gen SRY y la secuencia marcadora multicopia DYS14. Se aplicó un algoritmo diagnóstico muy estricto. En el caso de un resultado positivo para el ensayo de ambas pruebas específicas para el cromosoma $\mathrm{Y}$, se reportó como teniendo un feto masculino. En el caso de un resultado negativo, se estimó la presencia de ADN fetal mediante el uso de 24 polimorfismos de inserción/deleción bialélica o antígenos de grupo sanguíneo heredados del padre. Sólo si se confirmó la presencia de ADN fetal, se reportó un embarazo con feto femenino. Los resultados fueron comparados con el resultado del embarazo. Resultados: Fueron evaluadas un total de 201 mujeres. La mediana de edad gestacional fue $90 / 7$ semanas (rango intercuartil 8 0/7 a 10 0/7 semanas). Fue posible entregar un resultado en 189 de los 201 casos (94\%); en 10 casos, la presencia de ADN fetal no puso ser confirmada; en dos casos, se observó un aborto. El resultado del embarazo fue obtenido en 197 casos, incluyendo 105 embarazos con feto masculino, 81 con feto femenino y 11 abortos. La sensibilidad y especificidad de la prueba fue $100 \%$ (IC95\%: 96,5-100\% y 95,6-100\%, respectivamen- te). En los 10 casos en que la presencia de ADN fetal no pudo ser confirmado, el recién nacido fue de sexo femenino. Conclusión: La determinación no invasiva del sexo fetal en el plasma materno es altamente confiable y clínicamente aplicable. Nivel de evidencia: III.

\section{ANÁLISIS DE LA INVESTIGACIÓN}

\section{A. Relevancia clínica de la investigación}

El estudio pretende dar respuesta a la pregunta: ¿cuál es el rendimiento diagnóstico de la evaluación del sexo fetal en sangre materna?

Escenario clínico: La determinación del sexo fetal es una preocupación natural para los padres, curiosidad que puede ser satisfecha en la mayoría de los casos mediante la ecografía del II trimestre (2). Existe además, situaciones clínicas en que es apropiado conocer el sexo fetal de modo anticipado, principalmente en casos de mujeres embarazadas que portan una enfermedad hereditaria ligada al cromosoma $X$, o especialmente en pacientes con hijos afectados por hiperplasia suprarrenal congénita. En estos últimos la comprobación de un feto masculino da la oportunidad de suspender la terapia corticoidal instaurada (3). Para estos casos se ha propuesto la determinación del sexo fetal mediante pruebas invasivas: biopsia de vellosidades coriales o amniocentesis. Estos procedimientos invasivos reportan riesgo de daño fetal, que debe considerarse en proporción al beneficio de la información 
que se obtendrá. El desarrollo de pruebas no invasivas y confiables para la determinación del sexo fetal son indispensables. Se ha desarrollado pruebas para efectuar el diagnóstico del sexo fetal en el plasma materno estudiando ADN fetal libre en el plasma materno, con acuciosidad diagnóstica variable, aún en el ámbito de la investigación (4). Es indispensable conocer con precisión la capacidad diagnóstica de la determinación de sexo fetal en pruebas efectuadas en sangre materna, para establecer normas de manejo clínico confiables y seguras, en aquellos casos en que la determinación del sexo fetal puede cambiar el tratamiento de la embarazada.

\section{B. El estudio (1)}

Diseño: Se trata de un diseño de tipo prueba diagnóstica. Pacientes: Todas las mujeres a quienes se solicitó una prueba de diagnóstico de sexo fetal en sangre materna, no se excluyó pacientes, en un período de 7 años, en un mismo centro. Prueba diagnóstica evaluada: Se trata de un algoritmo diagnóstico basado en PCR en tiempo real para dos secuencias específicas del cromosoma $\mathrm{Y}$, secuencias específicas para confirmar ADN fetal. La prueba fue considerada positiva si ambos PCR dan resultado positivo. En ese caso se reporta un feto masculino. La prueba fue considerada negativa si ambos PCR resultan negativos, y se pudo confirmar la presencia de ADN fetal en la muestra mediante otros análisis por PCR. En ese caso se reporta un feto femenino. Si la prueba de PCR es negativa, pero no es posible confirmar la presencia de ADN fetal en la muestra, la prueba se informa como no concluyente, si las pruebas eran discordantes se repite el examen con la misma muestra. El resultado de la evaluación tardó entre 2 a 4 días. Estándar de comparación: El sexo fetal se conoció mediante cariotipo o ecografía o determinación del sexo del recién nacido. Resultados: Se evaluó a 201 mujeres, en 12 de ellas la prueba resultó no concluyente, se logró proponer un sexo en $189(94 \%)$ de los casos, y el sexo fetal fue finalmente conocido en 186 (93\%) casos. La capacidad diagnóstica de la prueba para determinación de cada sexo fetal se estimó a partir de los casos en los cuales se pudo conocer el sexo.

\section{Análisis crítico}

Validez interna: El estudio presentado tiene un diseño apropiado a la pregunta que motiva la investigación, se trata de un estudio de tipo prueba diagnóstica y cumple con la mayoría de los criterios para ser considerado como válido (5):

\section{Criterio} Cumplimiento

1 ¿Los clínicos enfrentaron incertidumbre diagnóstica?

2 ¿Existió comparación ciega con un estándar de referencia independiente?

3 ¿El estándar de referencia fue aplicado a todos los pacientes, independiente del resultado de la prueba en estudio?

El sexo fetal no pudo ser conocido en 15 embarazos, 11 abortos y 4 pérdidas de seguimiento, información que pudo haber cambiado el rendimiento diagnóstico. El diagnóstico de sexo fetal femenino no es detectado directamente, si no inferido por resultados negativos de secuencias para el cromosoma $\mathrm{Y}$, con confirmación de ADN fetal, siendo una de las limitantes del método. El algoritmo no fue aplicado de la misma manera en todas las pacientes del estudio, pues una segunda secuencia para el cromosoma $Y$ fue incorporado luego de las primeras 48 pacientes. Si bien el algoritmo completo puede ser considerado como un solo test, no se describe la manera en la cual se deriva el algoritmo ni como se derivan los criterios utilizados para catalogar a los test como no concluyentes. Ante la ausencia de una sola secuencia de genes que permita predecir el sexo fetal con sangre materna en embarazos iniciales, el uso de varias secuencias y sus diferentes valores aparece promisorio. Conocer el aporte individual de cada uno de los criterios puede permitir métodos sistemáticos de generación de algoritmos diagnósticos, que permitan estimar en forma más clara la capacidad diagnóstica de algoritmos y la probabilidad diagnóstica en la paciente individual.

\begin{tabular}{lcccc}
\hline $\begin{array}{l}\text { Capacidad diagnóstica } \\
\text { según sexo fetal }\end{array}$ & $\begin{array}{c}\text { Sensibilidad } \\
(\%)\end{array}$ & $\begin{array}{c}\text { Especificidad } \\
(\%)\end{array}$ & LR (+) & LR (-) \\
Sexo masculino & 100 & 100 & no calculable & no calculable \\
Sexo femenino & 87,7 & 100 & no calculable & 0,12 \\
\hline
\end{tabular}

Nota: Cálculos efectuados para sexo masculino asumiendo que resultado informado como femenino o no concluyente es un verdadero negativo. Cálculos efectuados para sexo femenino asumen los 10 resultados no concluyentes como un falso negativo. 
Validez externa: La prueba de PCR en tiempo real no está disponible en todos los centros lo que limita su aplicabilidad, sin embargo, la metodología empleada por los autores está descrita con suficiente detalle como para ser replicada en escenarios en que se disponga del equipamiento y los recursos necesarios.

Comentario: Se trata de un estudio con moderado riesgo de sesgo, que muestra que el sexo fetal pudo ser detectado con alto rendimiento en los pacientes con resultado disponible por medio de un algoritmo de estudio del ADN fetal. Se acertó en el $100 \%$ de los casos en que se concluye feto masculino y en el $87,7 \%$ de los casos en el cual se conoció el sexo femenino. En el $6 \%$ no fue posible entregar un resultado de la prueba. Desde un punto de vista clínico los resultados son alentadores, pues cuando es posible obtener resultado para la prueba diagnóstica, se podría confiar en su resultado. Es posible que nuevos estudios sobrepasen las limitaciones metodológicas evidenciadas en el pre- sente estudio y permitan una estimación aún más precisa de la capacidad diagnóstica de este test.

\section{REFERENCIAS}

1. Scheffer PG, Van der Schoot CE, Page-Christiaens GC, Bossers B, Van Erp F, De Haas M. Reliability of fetal sex determination using maternal plasma. Obstet Gynecol 2010;115(1):117-26.

2. Odeh M, Granin V, Kais M, Ophir E, Bornstein J. Sonographic fetal sex determination. Obstet Gynecol Surv 2009;64(1):50-7.

3. Nimkarn S, New Ml. Prenatal diagnosis and treatment of congenital adrenal hyperplasia due to 21-hydroxylase deficiency. Mol Cell Endocrinol 2009;300(1-2):192-6.

4. Wright $\mathrm{CF}$, Burton $\mathrm{H}$. The use of cell-free fetal nucleic acids in maternal blood for non-invasive prenatal diagnosis. Hum Reprod Update 2009;15(1):139-51.

5. Vera CM, Letelier LM, Carvajal JA. Guía para el análisis crítico de estudios que evalúan exámenes diagnósticos. Rev Chil Obstet Ginecol 2005;70(3):196-202. 